\title{
UK National Survey of Gastroenterologists' attitudes and barriers toward therapeutic drug monitoring of anti-TNF therapy in inflammatory bowel disease
}

\author{
Gaurav B Nigam, ${ }^{1}$ Shadab Nayeemuddin, ${ }^{1}$ Evangelos Kontopantelis, ${ }^{2}$ \\ Bu'Hussain Hayee, ${ }^{3,4}$ Jimmy K Limdi (i) ${ }^{1,5}$
}

- Additional material is published online only. To view please visit the journal online (http://dx.doi.org/10.1136/ flgastro-2019-101372).

For numbered affiliations see end of article.

\section{Correspondence to}

Professor Jimmy K Limdi, Gastroenterology, Pennine Acute Hospitals NHS Trust, Manchester OL1 2JH, UK; Jimmy.Limdi@pat. nhs.uk

Received 23 November 2019 Revised 27 December 2019 Accepted 7 January 2020

Published Online First

24 January 2020

\section{SLinked}

- http://dx.doi.org/10.1136/ flgastro-2019-101366

\section{Check for updates}

(c) Author(s) (or their employer(s)) 2021. No commercial re-use. See rights and permissions. Published by BMJ.

\section{To cite: Nigam GB,}

Nayeemuddin $S$,

Kontopantelis $\mathrm{E}$, et al.

Frontline Gastroenterology

2021;12:22-29.

\begin{abstract}
Background Evidence supports use of therapeutic drug monitoring (TDM) in improving efficacy and cost-effectiveness of anti-tumour necrosis factor (TNF) therapy in inflammatory bowel disease (IBD). Our objective was to assess attitudes and barriers towards TDM use with anti-TNF's in the UK.

Methods A 17-question survey was distributed to members of the British Society of Gastroenterology by email.

Results Of 243 respondents (51.6\% male), 237 respondents met inclusion criteria. Of these, $46 \%$ were consultants (gastroenterologist, $\mathrm{GI}), 39.2 \%$ IBD nurse specialists (clinical nurse specialists, CNS), $14.8 \%$ registrars. TDM is used by $96.9 \%$ for secondary loss of response; $72.5 \%$ for primary non-response and $54.1 \%$ used TDM proactively. Barriers were time lag in receiving results (49.8\%), lack of awareness of guidelines (46.4\%) and cost (29.9\%). Clinicians working at a teaching hospital (OR 2.6, 95\% CI 0.71 to 9.8 ), IBD CNS and GI registrars (OR 2.6, $95 \% \mathrm{Cl} 0.7$ to 10 and OR $1.5,95 \% \mathrm{Cl} 0.3$ to 7.2 , respectively) were more likely to use TDM. Clinicians practising for $>20$ years (OR 4.1, 95\% $\mathrm{Cl} 0.4$ to 41.8 ) and a large volume IBD practice (>50\% IBD patients per month) were more likely to use TDM (OR 45.7, 95\% Cl 7.5 to 275 ). Proactive TDM, was more likely to be used in tertiary care (OR $2.25,95 \% \mathrm{Cl} 0.84$ to 6.1$)$, IBD CNS (OR 1.2, 95\% Cl 0.7 to 2.1) and clinicians managing $>50 \%$ IBD patients per month (OR $10.8,95 \% \mathrm{Cl} 1.3$ to 90.3 ). Clinicians with 5-9 years of experience in practice were more likely to use proactive TDM (OR 2.6 and $\mathrm{Cl} 1.04$ to 6.4).

Conclusion Validation of point of care and lower cost assays, reduced time lag from test
\end{abstract}

\section{Significance of this study}

What is already known on this topic

- A growing body of evidence supports the association of optimising anti-TNF trough levels with objective improvement in therapeutic outcomes in patients with inflammatory bowel disease (IBD) during maintenance therapy and also through induction. Reactive drug monitoring is supported by international guidelines. Data on attitudes, perceptions and barriers to the use of therapeutic drug monitoring (TDM) with anti-TNF therapy are limited and virtually no UK-specific data exist.

\section{What are the new findings}

- TDM with anti-TNF therapy is mainly performed reactively, to loss of response to treatment. Clinicians with specialist experience and in specialist centres are more likely to employ TDM in optimising outcomes. Significant barriers to uptake of TDM in optimising treatment are a lack of awareness of guidelines, time lag between test and result and cost of testing.

How might it impact on clinical practice in the foreseeable future

- There is urgent need for wider dissemination of knowledge and existing guidance on current paradigms with TDM with anti-TNF therapy in patients with IBD. Validation of point of care and lower cost assays, reduced time lag from test to result and lower cost of testing may improve uptake. These measures are urgently needed to improve outcomes in patients with IBD treated with anti-TNF therapy. 
to result, lower cost of testing and dissemination of current recommendations may further optimise treatment strategies.

\section{INTRODUCTION}

The advent of anti-TNF therapy at the turn of the century has revolutionised the practice of inflammatory bowel disease (IBD). The implications of what can be achieved through abrogating immune-mediated tissue damage are significant and a better understanding of relevant outcomes, such as corticosteroid sparing, mucosal healing, reduction in hospitalisation, surgery and improvement in quality of life have redefined our perceptions around disease control. ${ }^{1-4}$

An appreciation of the potential disconnect between symptoms and objective measures of disease activity and evidence that uncontrolled inflammation may lead to progressive intestinal injury and irreversible bowel damage with complications has led to the concept of 'treating to target' (T2T). T2T informs the early treatment of patients at high risk for disease progression, to prevent or limit intestinal injury and disability. ${ }^{56}$ Resolution of symptoms and achieving mucosal healing are now key objectives of meaningful disease control. ${ }^{58}$ Although the therapeutic armamentarium is expanding, gastroenterologists (GIs) still have a relatively limited array of biological and novel therapies to choose from, with cost-effectiveness ever more important. It is imperative, therefore, to choose wisely and optimise treatment as accurately as possible. ${ }^{2}$ The recent approval of biosimilar infliximab and adalimumab driven by the aim of lowering cost and comparable efficacy, safety and immunogenicity to the originator will improve access to these highly effective therapies. ${ }^{9} 10$

It is well established that anti-TNF therapy is associated with risks of infusion reactions, immunogenicity and loss of response. ${ }^{11} \mathrm{Up}$ to $30 \%$ of patients have a primary non-response (PNR) and up to 50\% will have secondary loss of response (SLR) to anti-TNFs. ${ }^{12} 13$ Both these, may also be influenced by low or undetectable drug concentrations due to immune (antidrug antibodies) and non-immune clearance, determined significantly by inflammatory burden, body weight and serum albumin among other factors. ${ }^{12}{ }^{14}$ A growing body of evidence supports the association of higher anti-TNF trough levels with objective therapeutic outcomes during maintenance therapy, ${ }^{15-25}$ but also through induction. ${ }^{26-29}$ Taken together, recognised differences in anti-TNF pharmacokinetics, that translate into pharmacodynamic effects through hard end-points such as mucosal healing and potential for treatment failure from PNR and SLR, make it clear that a 'one-size fits-all' approach with fixed dosing and schedules, even if practical, is not logical.

Therapeutic drug monitoring (TDM) has been rapidly adopted for anti-TNF dose optimisation and may be defined as 'drug concentration measurement with adjustment of the dose and/or dosing intervals in order to achieve and maintain serum concentration within a certain therapeutic range to optimise treatment outcomes. ${ }^{30-33}$ In the case of biological therapies, antidrug antibodies are an integral part of this assessment.

TDM is typically performed in a reactive manner wherein serum levels are checked when there is a suspicion of loss of response with confirmed active disease. ${ }^{15-23} 30$ It has been shown to be cost-effective compared with empiric dose escalation. ${ }^{24}{ }^{34-36}$ Proactive TDM on the other hand, is performed at predefined time-points, irrespective of symptoms and with the aim of preventing 'under-dosing' from triggering a flare of disease or indeed even to potentially de-escalate in case of 'supra-therapeutic' levels. ${ }^{26-30}$ The use of TDM, at least reactively, is now supported by international IBD guidelines. ${ }^{31-33} 37-40$

Modern definitions of disease control involving the composite assessment of symptoms, patient reported outcomes with the 'hard' end-point of mucosal healing, make a compelling case for the optimisation of treatment using TDM, particularly when options after anti-TNF may be limited. There are limited data on attitudes, perceptions and barriers to the use of TDM with anti-TNF therapy and virtually no UK-specific data exist.

We conducted a UK nationwide survey on the use of TDM with anti-TNF therapy.

Our primary aim was to describe the proportion of GIs employing TDM, the clinical setting in which this was used and to identify barriers to the use of TDM in practice. Our secondary aim was to identify the clinical scenarios in which TDM would be used by UK GIs if all perceived barriers to TDM were removed.

\section{METHODS}

\section{Study design}

A 17-question survey (online supplementary appendix 1), was adapted with permission from a similar study conducted in the USA. ${ }^{41}$ This was then placed on an online survey tool. The questionnaire was approved by the Chair of the British Society of Gastroenterology (BSG) IBD section and an invitation with a link to complete the same was sent out to over 500 consultants and over 100 higher specialist trainees (registrar/ fellow) members of the BSG between June and October 2018. A link to the questionnaire was also included in the monthly BSG e-newsletter. The invitation with a link to the questionnaire was also distributed via the Royal College of nursing IBD network to over 300 IBD clinical nurse specialists (CNS). The study was registered with and approved by the Research and Innovation department of the Pennine Acute Hospitals National Health Service Trust.

Participants who did not treat patients with IBD or treating $<5$ IBD patients per month and/or having 
no patients on anti-TNF therapy every month were excluded from the study.

Demographic information sought from the participants included their age, sex, their grades (consultant, higher specialist trainee/registrar, IBD clinical nurse specialist) number of years in practice since specialist qualification or accreditation for gastroenterology (as applicable) and place of work (district general hospital, tertiary centre, university teaching hospital and/or private practice). Additionally, information was collected from respondents regarding the proportion of patients with IBD seen in their clinical practice, numbers of patients with IBD treated personally in a 1 -month period and numbers treated with anti-TNF therapy per month. We also sought details around the use of TDM using a Likert 5-point scales ranging from strongly agree to strongly disagree, to identify levels of agreement or disagreement with potential barriers to using TDM.

\section{Statistical analysis}

The data were analysed by using Stata V.15. All variables were categorical and expressed as frequencies and percentages. Univariate logistic regressions were used to examine associations between available variables and the outcomes of interest, use of TDM and proactive TDM. Associations were reported as ORs, along with their 95\% CIs.

\section{RESULTS}

Responses were received from 243 participants, of which 237 met inclusion criteria (six clinicians reported treating less than five IBD patients per month and were therefore excluded from further analysis). Baseline characteristics of all the participants are depicted in table 1.

\section{Practice of TDM}

Of all the participants included in the analysis. $96.6 \%$ $(n=229 / 237)$ used TDM in their current practice. Of these 229 participants, $96.9 \%(n=222)$ used TDM for SLR; 72.5\% $(n=166)$ for PNR; 37.1\% $(n=85)$ used it before restarting anti-TNF therapy after a drug holiday and $54.1 \%(\mathrm{n}=124)$ used it proactively (figure 1$)$. Among those who performed proactive TDM, 52\% $(n=65)$ checked drug levels at least once a year. Only $36.7 \%(n=87)$ respondents worked in a trust/practice setting, which had negotiated a free TDM package with their anti-TNF supplier.

A univariate analysis of independent factors associated with TDM suggested that clinicians working at a teaching hospital were more likely to use TDM compared with clinicians at a district general hospital (OR 2.6, 95\% CI 0.71 to 9.8). Clinicians practicing for $>20$ years were more likely to check TDM than less experienced clinicians (OR 4.1,95\% CI 0.4 to 41.8). Clinicians with a large volume IBD practice (>50\% IBD patients per month) were more likely to
Table 1 Participant demographic and clinical characteristics

\begin{tabular}{|c|c|}
\hline Participants & $\mathrm{N}=237$ \\
\hline \multicolumn{2}{|l|}{ Gender } \\
\hline Male & $122(51.5 \%)$ \\
\hline Female & $115(48.5 \%)$ \\
\hline \multicolumn{2}{|l|}{ Practice setting } \\
\hline District general hospital & $123(51.9 \%)$ \\
\hline Tertiary centre & $41(17.3 \%)$ \\
\hline Teaching hospital & $103(43.5 \%)$ \\
\hline Private practice & $9(3.8 \%)$ \\
\hline \multicolumn{2}{|l|}{ Grade } \\
\hline Consultant gastroenterologist & $109(46 \%)$ \\
\hline Registrar/fellow (gastroenterology) & $35(14.8 \%)$ \\
\hline IBD nurse specialist (nurse practitioner) & $93(39.2 \%)$ \\
\hline \multicolumn{2}{|l|}{ Age } \\
\hline $25-34$ & $40(16.9 \%)$ \\
\hline $35-44$ & $78(32.9 \%)$ \\
\hline $45-54$ & $93(39.2 \%)$ \\
\hline $55-64$ & $22(9.3 \%)$ \\
\hline$>65$ & $4(1.7 \%)$ \\
\hline \multicolumn{2}{|c|}{ Years (post gastroenterology certification) in practice } \\
\hline Still in training & $30(12.6 \%)$ \\
\hline$<1$ & $9(3.8 \%)$ \\
\hline $1-4$ & $40(16.9 \%)$ \\
\hline $5-9$ & $50(21.1 \%)$ \\
\hline $10-19$ & $68(28.7 \%)$ \\
\hline$>20$ & $40(16.9 \%)$ \\
\hline \multicolumn{2}{|c|}{ Per cent of patients with IBD in individual practice } \\
\hline$<10$ & $2(0.8 \%)$ \\
\hline $11-25$ & $44(18.6 \%)$ \\
\hline $26-50$ & $51(21.5 \%)$ \\
\hline$>50$ & $140(59.1 \%)$ \\
\hline \multicolumn{2}{|l|}{ Patients with IBD treated per month (N) } \\
\hline $5-10$ & $10(4.2 \%)$ \\
\hline $11-20$ & $34(14.3 \%)$ \\
\hline $20-30$ & $30(12.7 \%)$ \\
\hline$>30$ & $163(68.8 \%)$ \\
\hline \multicolumn{2}{|l|}{ Patients treated with anti-TNF in a month } \\
\hline $1-4$ & $34(14.3 \%)$ \\
\hline $5-10$ & $59(24.9 \%)$ \\
\hline $11-20$ & $144(60.8 \%)$ \\
\hline
\end{tabular}

$\mathrm{IBD}$, inflammatory bowel disease.

check TDM than those seeing fewer IBD patients (OR $45.6,95 \%$ CI 7.5 to 275$)$. IBD CNS and gastroenterology specialist registrars used TDM more often, when compared with consultants (OR 2.6, 95\% CI 0.69 to 10 and $\mathrm{OR} 1.5,95 \% \mathrm{CI} 0.3$ to 7.2 , respectively) (table 2). Proactive TDM (table 3), was more likely to be used by clinicians working in a tertiary care setting (OR 2.25, 95\% CI 0.84 to 6.05), clinicians managing a proportion of $>50 \%$ IBD patients per month (OR $10.8,95 \%$ CI 1.2 to 90 ) and clinicians with 5-9 years of experience in practice (OR 2.6 and CI 1.04 to 6.42) and IBD CNS (OR 1.2, 95\% CI 0.7 to 2.1). 


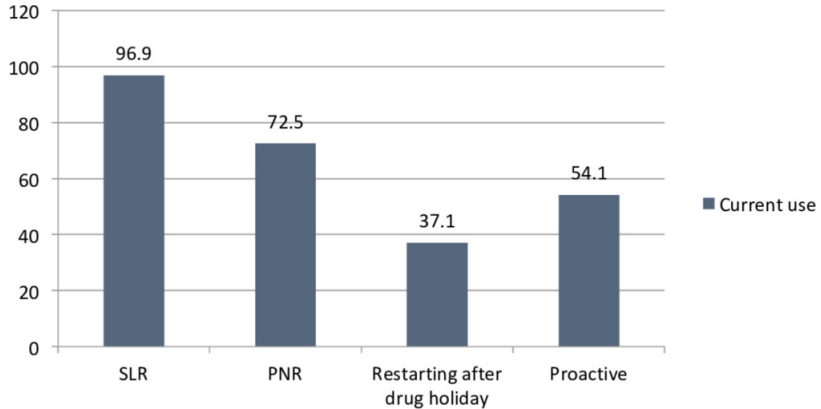

Figure 1 Current use of therapeutic drug monitoring. PNR, primary non-response; SLR, secondary loss of response.

The main barriers for TDM use reported by the respondents were time lag in receiving results $(49.8 \%$, $\mathrm{n}=118)$ and lack of clinical guidelines recommending TDM (46.4\%, $\mathrm{n}=110)$. A third of the respondents $(29.9 \%, n=71)$ felt that the cost of TDM was a barrier for use in their practice. Respondents mostly disagreed or strongly disagreed that uncertainty about availability of the test in their hospital/practice $(77.2 \%, \mathrm{n}=183)$ was a barrier for TDM use. Similarly, a majority of the respondents did not consider lack of overall knowledge of TDM $(70.5 \%, n=167)$, lack of knowledge on interpretation and use of TDM $(70 \%, \mathrm{n}=166)$, TDM being cumbersome and/or time consuming (68.4\%, $\mathrm{n}=162$ ) and lack of a good evidence base for use of $\operatorname{TDM}(59.5 \%, \mathrm{n}=141)$ as barriers in its use (figure 2).

If all barriers to TDM use were removed, seven out of the eight respondents currently not practicing TDM would perform it more frequently. Among them $85.7 \%$ $(n=6)$ would check TDM for SLR, 71.4\% $(n=5)$ for PNR, 57.1\% $(n=4)$ when restarting after a drug

\begin{tabular}{|c|c|c|}
\hline Variable & OR & $95 \% \mathrm{Cl}$ \\
\hline \multicolumn{3}{|l|}{ Practice setting } \\
\hline Tertiary hospital & 1 & \\
\hline Teaching hospital & 2.6 & 0.71 to 9.8 \\
\hline Private practice & 0.16 & 0.01 to 1.8 \\
\hline \multicolumn{3}{|l|}{ Grade } \\
\hline Registrar (gastroenterology) & 1.5 & 0.3 to 7.2 \\
\hline IBD nurse specialist & 2.6 & 0.7 to 10 \\
\hline \multicolumn{3}{|l|}{ Years in practice } \\
\hline$<1$ & 0.83 & 0.07 to 9.1 \\
\hline $1-4$ & 0.52 & 0.12 to 2.2 \\
\hline $5-9$ & 2.53 & 0.4 to 16.1 \\
\hline 10-19 & 3.41 & 0.5 to 21.5 \\
\hline$>20$ & 4.14 & 0.4 to 41.8 \\
\hline \multicolumn{3}{|l|}{ Patients with IBD (n) } \\
\hline $11-25$ & 7.8 & 1.5 to 41.4 \\
\hline $26-50$ & 11.7 & 2.1 to 65.7 \\
\hline$>50$ & 45.7 & 7.6 to 275.4 \\
\hline
\end{tabular}

$\mathrm{IBD}$, inflammatory bowel disease.
Table 3 Univariate analysis comparing factors related to proactive therapeutic drug monitoring use

\begin{tabular}{lll}
\hline Variable & OR & $95 \% \mathrm{Cl}$ \\
\hline Practice setting & & \\
\hline $\begin{array}{l}\text { Tertiary hospital } \\
\text { Teaching hospital }\end{array}$ & 2.25 & 0.8 to 6.1 \\
\hline $\begin{array}{l}\text { Private practice } \\
\text { Grade }\end{array}$ & 1.1 & 0.61 to 1.9 \\
\hline Registrar (gastroenterology) & 1.2 & 0.07 to 19.8 \\
\hline IBD nurse specialist & 0.5 & 0.2 to 1.05 \\
\hline $\begin{array}{l}\text { Years in practice } \\
<1\end{array}$ & 1.2 & 0.7 to 2.12 \\
\hline $1-4$ & 0.83 & 0.18 to 3.9 \\
\hline $5-9$ & 2.02 & 0.8 to 5.16 \\
\hline $10-19$ & 2.58 & 1.04 to 6.4 \\
\hline$>20$ & 1.5 & 0.63 to 3.5 \\
\hline Per cent of patients with IBD & 2.13 & 0.83 to 5.5 \\
\hline $11-25$ & & \\
\hline $26-50$ & 4.8 & 0.5 to 42.8 \\
\hline 50 & 4.5 & 0.5 to 39.5 \\
\hline
\end{tabular}

IBD, inflammatory bowel disease.

holiday and 71.4\% $(\mathrm{n}=5)$ would check it proactively (figure 3). 85.7\% $(n=6)$ of these would check TDM proactively at once a year if all barriers were removed.

\section{DISCUSSION}

There is substantial variation in anti-TNF drug exposure and response to treatment, underscoring the role of treatment optimisation based on TDM. Consequently, TDM has emerged as the new standard of care for optimising anti-TNF therapy in IBD, with reactive TDM being endorsed for assessment of PNR and SLR by recent international guidelines. ${ }^{31} 32$ 37-40 42 There is a dearth of literature on clinicians' attitudes, perceptions and barriers to the use of anti-TNF TDM, with virtually no data from the UK. ${ }^{41}$ This is the first UK National Survey on TDM among clinicians treating IBD patients with anti-TNF therapies.

We found that the majority of respondents (96.6\%) reported using TDM in their practice with 96\% employing TDM for assessment of SLR and $72 \%$ for PNR. This resonates with findings from a recent a US study wherein $87 \%$ of GIs utilised TDM for SLR and $66 \%$ for PNR, respectively. ${ }^{41}$ Practice in an academic setting (teaching hospital or tertiary centre), clinicians with over 20 years experience in treating IBD, seeing a large number of IBD patients $(>50 \%$ in their practice) and seeing IBD nurse specialists was associated with greater use of TDM. In contrast, low volume IBD practice and solo private practice was associated with less TDM use.

Only 54\% in comparison reported using proactive TDM which was higher than that reported in a US survey by Grossberg et al. ${ }^{41}$ All predictors of reactive TDM held true for proactive monitoring, with the only 

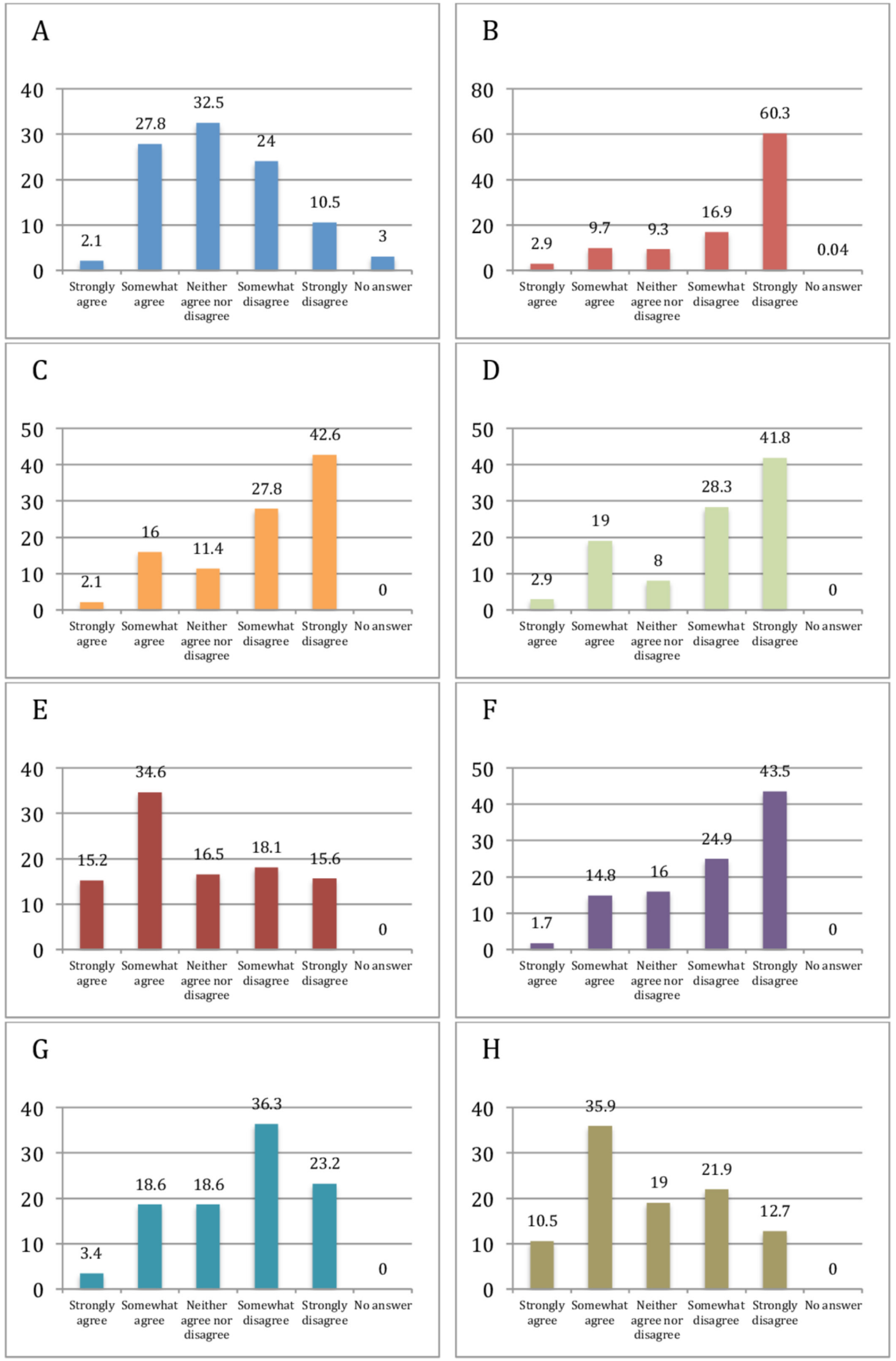

Figure 2 Barriers to therapeutic drug monitoring (TDM): test is expensive (A); uncertainty about availability in my trust/practice (B); lack of overall knowledge of TDM (C); lack of knowledge on how to interpret and what to do with the results of TDM (D); time lag from serum sampling to results of TDM (E); TDM is cumbersome and/or time consuming (F); lack of good evidence-based medicine of the usefulness of TDM in inflammatory bowel disease $(G)$; lack of clinical guidelines recommending the use of TDM $(H)$. 


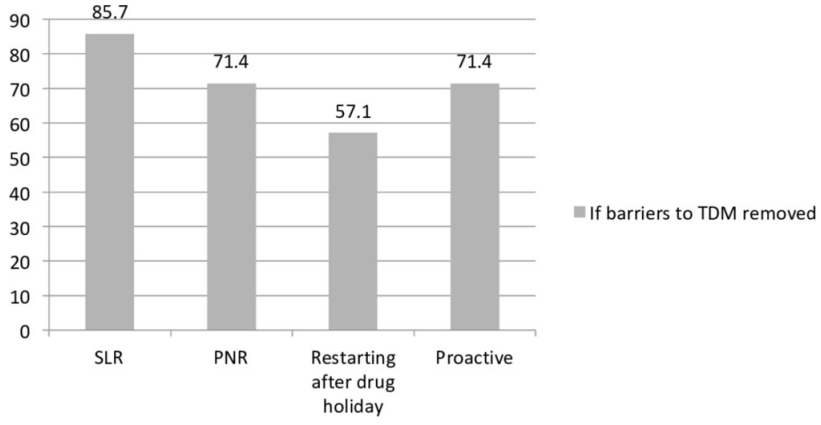

Figure 3 If barriers to TDM removed. PNR, primary non-response; SLR, secondary loss of response; TDM, therapeutic drug monitoring.

difference being clinicians within 5-9 years of practice since specialty certification utilising it more than other subset categories. This is likely a reflection of the growing body of evidence in recent years demonstrating the merits of proactive TDM during maintenance therapy with improved outcomes. ${ }^{2628} 2943$ The TAXIT trial demonstrated that proactive TDM was associated with less undetectable concentrations and relapse compared with clinically based dosing. ${ }^{26}$ Proactive TDM has also been associated with less treatment failure, lower rates of IBD-related hospitalisation or surgery, risks of antidrug antibodies and serious infusion reactions as compared with reactive testing. ${ }^{43}$ Indeed, proactive TDM was also shown to be associated with longer duration of drug survival and fewer IBD-related hospitalisations compared with reactive TDM. ${ }^{44}$ Arguably, proactive TDM may be more compelling during induction when the disease may be most active and drug clearance at its highest. ${ }^{27} 334045$ A post-hoc analysis of the TAILORIX trial ${ }^{27}$ demonstrated that higher infliximab concentrations were associated with early endoscopic remission at week $12 .{ }^{45}$ These data make a strong case for the use of proactive TDM, but more robust data may be needed to translate into consensus/ guideline recommendation.

We explored the limitations or barriers to the wider acceptance and use of TDM. The main barriers for TDM use in our survey were time lag from serum sampling to receiving results, perceived lack of clinical guidelines recommending the use of TDM and high cost of the test as reported in the study by Grossberg et $a l .{ }^{41}$ Furthermore, our survey respondents, who were not using TDM, would use TDM more frequently if all barriers were removed.

Our respondents (70\%) did not report a lack of knowledge of TDM or its interpretation as being a limitation to its use, similar to the US survey. ${ }^{41}$ A recent UK study exploring understanding and interpretation of TDM using TDM based clinical scenarios, however, demonstrated marked heterogeneity in its practical use, understanding and interpretation. ${ }^{46}$ This makes sense when one acknowledges that TDM is a relatively newer concept although integrated through evidence into standard of care and that its use may still be limited by experience and awareness of various assays and the heterogeneity therein. It also makes a compelling case for a more robust approach through multidisciplinary care provided by experienced IBD clinicians. It is possible that population pharmacokinetics will identify parameters and sources of variability with dosing and enable clinicians to apply individual dosing using a dashboard system ${ }^{4748}$ to calculate the exact dose a patient should receive and at what time to maintain optimal drug concentrations. ${ }^{47} 48$ Meanwhile, 'point of care' assays may be able to rapidly measure trough concentrations enabling efficacy through speedy and accurate dose optimisation. ${ }^{30}{ }^{49}$ Reassuringly, TDM has been shown to be cost-effective compared with empiric dose escalation. ${ }^{24} 34-36$

A major strength of our study is the inclusion of respondents with a wide variation of clinical experience, representing the 'real-world' UK practice of IBD. Despite our wide reach through national organisations, only a quarter of the total membership responded reflective of most survey-based studies. ${ }^{41}$ We acknowledge an element of selection bias, as it is entirely plausible that our respondents were clinicians with a particular interest in IBD who use TDM in the management of their patients. Consequently, our sample size was small. As such, there may be an over-estimate of the use of TDM within this study compared with that of more 'general' GIs who may not have responded to the survey due to possible unfamiliarity with current concepts and knowledge of TDM with anti-TNF therapy. Knowledge gaps and inconsistencies with the use of TDM with anti-TNF therapy despite international guidelines endorsing their applicability for optimising therapy, ${ }^{31-33} 37-40$ represent an important area of unmet need ${ }^{46-48}$ which should be addressed through educational initiatives, seminars and publication with wide access to practising GIs and IBD teams. Finally, we did not enquire about specific scenarios where respondents use TDM, such as Crohn's disease and its phenotypes where more robust evidence currently exists. This is a science in evolution, but it will be important to see how and where clinicians employ TDM in IBD practice within specific phenotypes and clinical scenarios as access and time to results improve.

In conclusion we found that TDM is already being used widely in current clinical practice in the UK, mainly in the reactive setting but over just $50 \%$ of clinicians using it proactively as well. Significant barriers to TDM use were time lag, perceived lack of clinical guidance and high cost of the test. Validation of point of care testing, lower cost assays and wider dissemination of guidance with updated recommendations to TDM use may further optimise treatment with anti-TNF therapies. Dashboard systems and novel approaches using population pharmacokinetics may serve to optimise drug exposure through 
predictive modelling. Finally, published literature so far only has limited data on the use of TDM in resource rich settings. Further exploration on TDM use in low-income and middle-income countries with limited biological choices make a compelling argument for optimisation of available therapies and is worthy of exploration. TDM of biological therapies is a science in evolution with exciting implications for clinical research.

\section{Article summary}

The use of TDM in the UK remains limited to GIs working at a teaching hospital and large volume IBD centres. Time lag in receiving results, lack of awareness of clinical guidelines and cost represent limited use of TDM. Validation of point of care and lower cost assays, reduced time lag to result and wider dissemination of updated recommendations may improve optimisation of TDM with anti-TNF therapies.

\section{Author affiliations \\ ${ }^{1}$ Gastroenterology, Pennine Acute Hospitals NHS Trust, Manchester, UK ${ }^{2}$ Division of Informatics, Imaging \& Data Sciences; Faculty of Medicine, Biology \& Health, The University of Manchester, Manchester, UK \\ ${ }^{3}$ Gastroenterology, King's College Hospital NHS Foundation Trust, London, UK \\ ${ }^{4}$ Gastroenterology, King's College London, London, UK \\ ${ }^{5}$ Gastroenterology, The University of Manchester, Manchester, UK}

Contributors JKL conceived the study. GBN, SN and JKL prepared and modified the questionnaire. BH crucially evaluated the questionnaire. JKL, GBN and SN wrote the manuscript. EK performed statistical analysis. All authors (GBN, SN, EK, BH, JKL) critically evaluated the manuscript and approved the final version.

Funding The authors have not declared a specific grant for this research from any funding agency in the public, commercial or not-for-profit sectors.

Competing interests JKL has received consultancy and speaker fees from MSD, Abbvie, Janssen, Pfizer and Takeda and research support from Takeda pharmaceuticals.

Patient consent for publication Not required.

Provenance and peer review Not commissioned; externally peer reviewed.

Data availability statement Data are available upon reasonable request.

ORCID iD

Jimmy K Limdi http://orcid.org/0000-0002-1039-6251

\section{REFERENCES}

1 Ford AC, Sandborn WJ, Khan KJ, et al. Efficacy of biological therapies in inflammatory bowel disease: systematic review and meta-analysis. Am J Gastroenterol 2011;106:644-59. quiz 60.

2 Colombel J-F, Narula N, Peyrin-Biroulet L. Management strategies to improve outcomes of patients with inflammatory bowel diseases. Gastroenterology 2017;152:351-61.

3 Cholapranee A, Hazlewood GS, Kaplan GG, et al. Systematic review with meta-analysis: comparative efficacy of biologics for induction and maintenance of mucosal healing in Crohn's disease and ulcerative colitis controlled trials. Aliment Pharmacol Ther 2017;45:1291-302.

4 Feagan BG, Reinisch W, Rutgeerts P, et al. The effects of infliximab therapy on health-related quality of life in ulcerative colitis patients. Am J Gastroenterol 2007;102:794-802.
5 Peyrin-Biroulet L, Sandborn W, Sands BE, et al. Selecting therapeutic targets in inflammatory bowel disease (STRIDE): determining therapeutic goals for Treat-to-Target. Am J Gastroenterol 2015;110:1324-38.

6 Peyrin-Biroulet L, Panés J, Sandborn WJ, et al. Defining disease severity in inflammatory bowel diseases: current and future directions. Clin Gastroenterol Hepatol 2016;14:348-54.

7 Shah SC, Colombel J-F, Sands BE, et al. Mucosal healing is associated with improved long-term outcomes of patients with ulcerative colitis: a systematic review and meta-analysis. Clin Gastroenterol Hepatol 2016;14:1245-55.

8 Shah SC, Colombel J-F, Sands BE, et al. Systematic review with meta-analysis: mucosal healing is associated with improved long-term outcomes in Crohn's disease. Aliment Pharmacol Ther 2016;43:317-33.

9 Jørgensen KK, Olsen IC, Goll GL, et al. Switching from originator infliximab to biosimilar CT-P13 compared with maintained treatment with originator infliximab (NORSWITCH): a 52-week, randomised, double-blind, noninferiority trial. Lancet 2017;389:2304-16.

10 Fiorino G, Ruiz-Argüello MB, Maguregui A, et al. Full interchangeability in regard to immunogenicity between the infliximab reference biologic and biosimilars CT-P13 and Sb2 in inflammatory bowel disease. Inflamm Bowel Dis 2018;24:601-6.

11 Baert F, Noman M, Vermeire S, et al. Influence of immunogenicity on the long-term efficacy of infliximab in Crohn's disease. N Engl J Med 2003;348:601-8.

12 Ben-Horin S, Chowers Y. Review article: loss of response to anti-TNF treatments in Crohn's disease. Aliment Pharmacol Ther 2011;33:987-95.

13 Kennedy NA, Heap GA, Green HD, et al. Predictors of antiTNF treatment failure in anti-TNF-naive patients with active luminal Crohn's disease: a prospective, multicentre, cohort study. Lancet Gastroenterol Hepatol 2019;4:341-53.

14 Ordás I, Mould DR, Feagan BG, et al. Anti-Tnf monoclonal antibodies in inflammatory bowel disease: pharmacokineticsbased dosing paradigms. Clin Pharmacol Ther 2012;91:63546.

15 Bortlik M, Duricova D, Malickova K, et al. Infliximab Trough levels may predict sustained response to infliximab in patients with Crohn's disease. J Crohns Colitis 2013;7:736-43.

16 Cornillie F, Hanauer SB, Diamond RH, et al. Postinduction serum infliximab Trough level and decrease of C-reactive protein level are associated with durable sustained response to infliximab: a retrospective analysis of the accent I trial. Gut 2014;63:1721-7.

17 Levesque BG, Greenberg GR, Zou G, et al. A prospective cohort study to determine the relationship between serum infliximab concentration and efficacy in patients with luminal Crohn's disease. Aliment Pharmacol Ther 2014;39:1126-35.

18 Papamichael K, Rakowsky S, Rivera C, et al. Association Between Serum Infliximab Trough Concentrations During Maintenance Therapy and Biochemical, Endoscopic, and Histologic Remission in Crohn's Disease. Inflamm Bowel Dis 2018;24:2266-71.

19 Papamichael K, Rakowsky S, Rivera C, et al. Infliximab Trough concentrations during maintenance therapy are associated with endoscopic and histologic healing in ulcerative colitis. Aliment Pharmacol Ther 2018;47:478-84.

20 Yarur AJ, Kanagala V, Stein DJ, et al. Higher infliximab Trough levels are associated with perianal fistula healing in patients with Crohn's disease. Aliment Pharmacol Ther 2017;45:93340.

21 Strik AS, Löwenberg M, Buskens CJ, et al. Higher anti-TNF serum levels are associated with perianal fistula closure in Crohn's disease patients. Scand J Gastroenterol 2019;54:4538. 
22 Paul S, Moreau AC, Del Tedesco E, et al. Pharmacokinetics of adalimumab in inflammatory bowel diseases: a systematic review and meta-analysis. Inflamm Bowel Dis 2014;20:128895.

23 Juncadella A, Papamichael K, Vaughn BP, et al. Maintenance adalimumab concentrations are associated with biochemical, endoscopic, and histologic remission in inflammatory bowel disease. Dig Dis Sci 2018;63:3067-73.

24 Limdi JK. Golimumab for ulcerative colitis: adding perspective to the pursuit. Frontline Gastroenterol 2018;9:232-3.

25 Samaan MA, Pavlidis P, Digby-Bell J, et al. Golimumab: early experience and medium-term outcomes from two UK tertiary IBD centres. Frontline Gastroenterol 2018;9:221-31.

26 Vande Casteele N, Ferrante M, Van Assche G, et al. Trough concentrations of infliximab guide dosing for patients with inflammatory bowel disease. Gastroenterology 2015;148:1320-9.

27 D'Haens G, Vermeire S, Lambrecht G, et al. Increasing Infliximab Dose Based on Symptoms, Biomarkers, and Serum Drug Concentrations Does Not Increase Clinical, Endoscopic, and Corticosteroid-Free Remission in Patients With Active Luminal Crohn's Disease. Gastroenterology 2018;154:134351.

28 Papamichael K, Vajravelu RK, Vaughn BP, et al. Proactive infliximab monitoring following reactive testing is associated with better clinical outcomes than reactive testing alone in patients with inflammatory bowel disease. J Crohns Colitis 2018;12:804-10.

29 Vaughn BP, Martinez-Vazquez M, Patwardhan VR, et al. Proactive therapeutic concentration monitoring of infliximab may improve outcomes for patients with inflammatory bowel disease. Inflamm Bowel Dis 2014;20:1996-2003.

30 Strik AS, Berends SE, Lowenberg M. Therapeutic drug monitoring-based dosing of TNF inhibitors in inflammatory bowel disease: the way forward? Expert Rev Clin Pharmacol 2019:1-7.

31 Feuerstein JD, Nguyen GC, Kupfer SS, et al. American gastroenterological association Institute guideline on therapeutic drug monitoring in inflammatory bowel disease. Gastroenterology 2017;153:827-34.

32 Mitrev N, Vande Casteele N, Seow CH, et al. Review article: consensus statements on therapeutic drug monitoring of antitumour necrosis factor therapy in inflammatory bowel diseases. Aliment Pharmacol Ther 2017;46:1037-53.

33 Papamichael K, Cheifetz AS, Melmed GY, et al. Appropriate therapeutic drug monitoring of biologic agents for patients with inflammatory bowel diseases. Clin Gastroenterol Hepatol 2019;17:1655-68.

34 Steenholdt C, Brynskov J, Thomsen Ole Østergaard, et al. Individualised therapy is more cost-effective than dose intensification in patients with Crohn's disease who lose response to anti-TNF treatment: a randomised, controlled trial. Gut 2014;63:919-27.

35 Velayos FS, Kahn JG, Sandborn WJ, et al. A test-based strategy is more cost effective than empiric dose escalation for patients with Crohn's disease who lose responsiveness to infliximab. Clin Gastroenterol Hepatol 2013;11:654-66.
36 Martelli L, Olivera P, Roblin X, et al. Cost-Effectiveness of drug monitoring of anti-TNF therapy in inflammatory bowel disease and rheumatoid arthritis: a systematic review. $J$ Gastroenterol 2017;52:19-25.

37 Lichtenstein GR, Loftus EV, Isaacs KL, et al. Acg clinical guideline: management of Crohn's disease in adults. Am J Gastroenterol 2018;113:481-517.

38 Rubin DT, Ananthakrishnan AN, Siegel CA, et al. Acg clinical guideline: ulcerative colitis in adults. Am J Gastroenterol 2019; 114:384-413.

39 Harbord M, Eliakim R, Bettenworth D, et al. Third European evidence-based consensus on diagnosis and management of ulcerative colitis. Part 2: current management. J Crohns Colitis 2017;11:769-84.

40 Lamb CA, Kennedy NA, Raine T, et al. British Society of gastroenterology consensus guidelines on the management of inflammatory bowel disease in adults. Gut 2019;68:s1-106.

41 Grossberg LB, Papamichael K, Feuerstein JD, et al. A Survey Study of Gastroenterologists' Attitudes and Barriers Toward Therapeutic Drug Monitoring of Anti-TNF Therapy in Inflammatory Bowel Disease. Inflamm Bowel Dis 2018;24:191-7.

42 Gomollón F, Dignass A, Annese V, et al. 3rd European Evidence-based Consensus on the Diagnosis and Management of Crohn's Disease 2016: Part 1: Diagnosis and Medical Management. ECCOJC 2017;11:3-25.

43 Papamichael K, Chachu KA, Vajravelu RK, et al. Improved long-term outcomes of patients with inflammatory bowel disease receiving proactive compared with reactive monitoring of serum concentrations of infliximab. Clin Gastroenterol Hepatol 2017;15:1580-8.

44 Papamichael K, Osterman MT, Siegel CA, et al. Using proactive therapeutic drug monitoring of anti-tumor necrosis factor therapy in inflammatory bowel disease: from an old concept to a future standard of care? Gastroenterology 2018;154:1201-2.

45 Dreesen E, D'Haens G, Baert F, et al. DOP047 Infliximab exposure predicts superior endoscopic outcomes in patients with active Crohn's disease: pharmacokineticpharmacodynamic analysis of TAILORIX. Journal of Crohn's and Colitis 2018;12:S063-4.

46 Samaan MA, Arkir Z, Ahmad T, et al. Wide variation in the use and understanding of therapeutic drug monitoring for antiTNF agents in inflammatory bowel disease: an inexact science? Expert Opin Biol Ther 2018;18:1271-9.

47 Dubinsky MC, Phan BL, Singh N, et al. Pharmacokinetic Dashboard-Recommended dosing is different than standard of care dosing in Infliximab-Treated pediatric IBD patients. Aaps J 2017;19:215-22.

48 Wojciechowski J, Upton RN, Mould DR, et al. Infliximab maintenance dosing in inflammatory bowel disease: an example for in silico assessment of adaptive dosing strategies. Aaps J 2017;19:1136-47.

49 Van Stappen T, Bollen L, Casteele NV, Vande Casteele N, et al. Rapid test for infliximab drug concentration allows immediate dose adaptation. Clin Transl Gastroenterol 2016;7:e206. 